\title{
CREATIVE INTEGRATION OF DESIGN THINKING AND STRATEGIC THINKING IN A DESIGN EDUCATION FRAMEWORK
}

\author{
Woonghee PARK ${ }^{1}$, Hyun-Kyung LEE (D) 2,* \\ ${ }^{1}$ Department of Design Intelligence, Graduate School of Communication and Arts, Yonsei University, \\ 50 Yonsei-ro Seodaemun-gu, 03722, Seoul, South Korea \\ ${ }^{2}$ Culture and Design Management Division, Faculty of Underwood International College, Yonsei \\ University, 50 Yonsei-ro Seodaemun-gu, 03722, Seoul, South Korea
}

Received 9 July 2020; accepted 22 November 2020

\begin{abstract}
With rapid globalization, designers are increasingly required to use creative integration of strategic thinking and design thinking to deal with complexity and uncertainty in an era of constant transformation. This study reviews the current status of design education to address the key question of how strategic thinking and design thinking can be enhanced creatively in undergraduate design students' education in South Korea. Furthermore, it investigates the key drivers for and barriers to the enhancement of strategic thinking and design thinking; seeks insights from successful design education programs; and gathers perspectives about strategic thinking and design thinking from design students, educators, and strategists. By using qualitative (in-depth interviews) and quantitative (a questionnaire) research methods, the study offers significant insights: (i) design undergraduates' short-sighted mind-set should be reshaped, (ii) additional practical, multicultural, and interdisciplinary applications of strategic thinking are needed to bridge the gap between theoretical and practical classes, and (iii) consistent stimulation is required to internalize strategic thinking and design thinking.
\end{abstract}

Keywords: creativity, design thinking, interdisciplinary application, strategic thinking, undergraduate level.

\section{Introduction}

With rapid globalization, the global market is becoming increasingly sophisticated, customers are demanding more product differentiation, and technologies are quickly changing through the introduction of new systems and concepts. As a result of these changes, designers are increasingly required to use strategic thinking and design thinking to deal with complexity and uncertainty in an era of constant transformation. Companies are pushed by the driving forces of innovation and globalization and seek strategic designers who can help them remain competitive (Woyke \& Atal, 2007). It is difficult for companies and organizations to survive

${ }^{\star}$ Corresponding author. E-mail: hyunkyunglee@yonsei.ac.kr 
in this fast-paced and changing market. As a result, design education now places greater emphasis on business (Design Management Institute, 2020; Borja de Mozota, 2003, pp. 9-13) and the role of design in fostering strategic thinking and design thinking (Herrmann \& Goldschmidt, 2013; Kefallonitis, 2007; Kumar, 2009). However, studies have indicated that design education in South Korea (SK) does not enable students to think in a strategic way, and thus, undergraduate design students in the country seriously lack the ability to think strategically (DesignDB, 2020; Shin \& Kim, 2012). In the business sector, many strategies have been developed for innovation, but as the times change, other obstacles continue to emerge (Anderson, 2004; Norman, 2013). As a result, existing methods alone have encountered limitations, and the design thinking theory, which is a methodology for solving problems creatively, has been revisited. Research on design thinking has been ongoing since the 1990s, and established from Hasso Plattner Institute of Design (HPID, Stanford University, United States (US)) in 2005. From the time, this useful solution for practical environment has been studied, such as design thinking toolkits for educators around the US (Brown, 2009a). However, domestic companies are still urgent to introduce overseas cases, and startups occupy most of the design industry, but they still have a slow development of educational methodologies to improve designers' design thinking ability.

The key question of this study is: How can strategic thinking and design thinking be enhanced in undergraduate design students' education in SK? To answer this question, this research reviews the current status of design education to provide background knowledge; investigates key drivers for and barriers to the enhancement of strategic thinking and design thinking in SK to understand the relationship between current design education and strategic thinking; seeks insights from successful design education programs in terms of improving strategic thinking and design thinking in different countries; and experiment two example classes applying the framework for two years (case studies); and gathers perspectives about strategic thinking and design thinking from design students, educators, and strategists.

\section{Creative integration of strategic thinking and design thinking}

Previous studies have used strategic thinking within the context of strategies, as it is interchangeable with other contexts (Nasi, 1991, p. 29). Strategic thinking has been identified mostly in business management literature, which focuses on the process of strategic thinking and decision making. In addition, strategic thinking has also been studied in psychology, with a focus on the elements that influence strategic thinking and decision making. However, there are limited studies regarding strategic thinking in the field of design. While there are some concepts or ideas similar to strategic thinking in the design world, there is no exact definition of strategic thinking in this context.

Instead of using the term "strategic thinking", McCullagh (2008, pp. 67-70) stated that designers must possess a broad-level or big-picture perspective to build a good strategy. Holston (2011, p. 66) discussed the attitudes that strategic designers should have and the actions they should undertake, but did not investigate the relationship between strategic thinking and designers' strategic roles. Although the definition of the role of strategic thinking in design has been limited in previous studies, the similarities between these subjects can be used to define strategic thinking in the design context. 
From Bonn's (2005) perspective, strategic thinking is a problem-solving process that deals with rationality and emotion. Design thinking occurs when a designer applies their sensibility and problem-solving skills to solve to a problem. Because client companies rely on the designer's problem-solving ability in a design context, Brown (2009b), chief executive officer of IDEO, argued that design thinking taps into all of the individual's problem-solving abilities. He described design thinking as a way to discover human needs and create solutions using the tools and mindsets of design practitioners whose methodologies address personal, social, and business challenges in creative ways. This process includes observation and collaboration, fast learning, visualization of ideas, rapid prototyping of concepts, and business analysis - which directly affect innovation and strategy (Brown, 2009b; Norman, 2013).

Additionally, strategic thinking and design thinking have another common feature. According to Martin (2009), design thinking can be positioned between analytical and intuitive thinking. Martin (2009, pp. 10-11) echoed this by claiming that balancing reliability in the context of analytical thinking and validity in the context of intuitive and creative thinking can lead to a new way of thinking. Similarly, strategic thinking is also a combination of the two different thinking processes. Bonn (2005) defined three elements of strategic thinking systems thinking, creativity, and vision - and argued that rational and creative thinking must coexist in the strategic thinking process. Therefore, strategic thinking and design thinking have mutually shared features; both are problem-solving processes that mix analytical and creative thinking. The main difference is that design thinking focuses on design, such as visualization and human-centered prototyping. Based on this literature review, this research uses the following definition.

Strategic thinking and design thinking for design major students could be a holistic and systemic perspective on how to "think" about business, environment, education, social, and economic problems, and an ability to "solve" the problems from the planning to the completion process by creating design strategies through strategic design skills and tools.

This research argues that in the design context, strategic thinking and design thinking are a combination of systemic attitudes and the strategic abilities to solve problems. Therefore, the terms "strategic thinking" and "design thinking" used in this research are based on the aforementioned definition. As strategic thinking and design thinking are considered to be important aspects that must be taught at the undergraduate level of design education, the next section will examine the current status of the design education program setting and determine the required improvements.

\section{Role of creativity in design education}

Creativity plays a role in many diverse fields, such as education, business, sciences, etc., and also in problem-solving and learning (Lee \& Breitenberg, 2010). There are many different views on creativity definitions, but the minimal lexical definition of creativity is "the ability to make or otherwise bring into existence something new, whether a new solution to a problem, a new method or device, or a new artistic object or form" (Britannica, 2020), or "bringing something novel into being" (Gaut \& Livingston, 2003). Runco (2007) points out that our educational system mostly emphasizes convergent thinking (finding one correct answer) 
and less divergent thinking (generating many ideas), whereas these two ways of thinking styles were proposed by Guilford. In the book Characteristics of Creativity, Guilford (1973, pp. 30-35) encourages us to "look critically at facts and ideas, test ideas, think of alternative methods and ideas, question and doubt, develop tolerance for new and unusual ideas, and to express their own ideas in new and unusual forms". According to Sarkar and Chakrabarti (2011), creativity is crucial for enabling innovation, and Casakin (2007) argues that creativity is required to solve design problems. Amabile et al. (1994) talk about "intrinsic motivation", which is the motivation for engaging in work mainly due to interest, engagement, and satisfaction, and creativity should be positively related to it. Thus, it is important to provide an environment where students are intrinsically motivated and where their interests can be increased and kept active (Anderson, 2003a, 2003b, 2004).

\section{Current formal design education}

\subsection{Current status of design education programs}

Education is the process of receiving or giving systematic instruction, especially at school or university. Education has been categorized as three forms of learning: formal, non-formal, and informal (Zaki Dib, 1988). Of these, formal education is curriculum-based education wherein educators teach and students learn. Why, then, is formal design education needed? In formal design education, students learn how to embrace tradition and gain the opportunity to experience the design field.

Formal design education around the world has started to integrate many disciplines and various curricula - such as design, business, and engineering - to foster strategic thinking. Daniel H. Pink's argument in the New York Times that "the MFA has replaced the MBA" caused a stir several years ago in the design and business education communities (Kurzweil, 2004). He argued that the fundamental skills and cognitive processes of the designer - holistic thinking, empathy, imagination, creativity, and visualization of problems and solutions have become more important in business than traditional analytic skills taught in Master of Business Administration programs (Lee \& Breitenberg, 2010).

This trend is not observed in one area alone; rather, it is being explored in Europe, the United Kingdom (UK), the US, and Asia. For instance, the Strategic Design and Management course at Parsons School of Design (US) has successfully integrated design and business through the incorporation of global team-based design projects. The Köln International School of Design (KISD, Technical University of Cologne, Germany) is also project oriented. Brunel University London (UK) is an example of the combination of design and engineering, and Lancaster University (LU, UK) has a joint program with the LU Management School and the Lancaster Institute for the Contemporary Arts (LU) to inspire students' thinking processes.

In response, numerous graduate programs in interdisciplinary design have emerged, including HPID; the Master in Product Development at Carnegie Mellon University (US); the Massachusetts Institute of Technology Media Lab (US); the Product Innovation Lab in North Carolina State University (US); Design Works at the University of Toronto (Canada); the International Design Business Management Program of Aalto University (AU, Finland); 
Copenhagen Institute of Interaction Design (Denmark); the Technical University of Munich (Germany); and the Faculty of Industrial Design Engineering of the Delft University of Technology (Netherlands).

While a variety of programs are available at the graduate level, only a few undergraduate transdisciplinary programs are currently offered, such as those at KISD, Design Academy Eindhoven (Netherlands), and Singapore University of Technology and Design (Singapore). This can be explained by the difficulties associated with teaching students at the undergraduate level to integrate knowledge from different fields. Furthermore, this becomes more challenging when design education is integrated with other disciplines with which it is not traditionally associated, such as technology or management. Despite these limitations, the development of courses for interdisciplinary education programs at the undergraduate level is becoming more popular. However, in many Asian countries, design education is yet to reach the strategic level. For example, although SK has attempted to merge some disciplines since 2009 (Ministry of Knowledge Economy, 2013) - for instance, engineering and design - the outcome is still limited in terms of enabling students to think in a strategic way.

To explore this issue, we present a case study of the Techno-Art Division (TAD) at Underwood International College (UIC, Yonsei University, SK). The purpose of presenting this case study is to examine the current status and potential of the interdisciplinary design education program through the lenses of the strategic thinking and design thinking processes, both of which encourage divergent thinking.

\subsection{Overview of the undergraduate interdisciplinary design program at Yonsei University, South Korea}

The TAD was created in 2012 as the first interdisciplinary undergraduate program in SK, integrating instructions from the design, technology, and management programs offered at the UIC. The TAD consists of three majors: Information and Interaction Design (IID), Creative Technology Management (CTM), and Culture and Design Management (CDM). While IID focuses on the field of information technology and interaction design, CTM focuses on information technology management and entrepreneurship, and CDM focuses on product design and marketing.

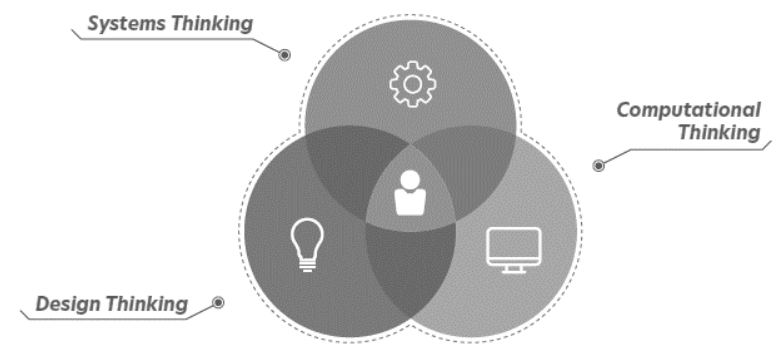

Figure 1. Undergraduate interdisciplinary design program (source: created by authors) 
As shown on Figure 1, each major places slightly different emphasis on the integration of design, technology, and management. Information and interaction design focuses on design practice with relevant technology, culture and design management focuses on cultural planning, and culture and technology management focuses on management of the information technology business. However, they are all based on placing design thinking and strategic thinking methods at the center of integration.

One special system we would like to emphasize here is Design Factory Korea (DFK). DFK, an educational platform, is part of the Design Factory Global Network (DFGN) an innovative and interdisciplinary network creating collaborations between like-minded people, projects, and platforms. DFGN conducts regular meetings to share experiences, and discuss and research educational methods in engineering, business, and design for the new era. The concept originates from Finland's AU, and the idea has been introduced to 13 countries (Finland, China, Australia, Chile, Switzerland, SK, Portugal, Netherlands, Latvia, Turkey, Columbia, the US, Spain, New Zealand, Brazil, Belgium, Poland, Japan, Singapore, Estonia, and Germany). One of DFK's most distinguishing features is the innovative educational philosophy which actively provides solutions to practical problems faced by companies and societies through collaborations and the exchange of ideas between students from diverse backgrounds.

\section{Methodology}

To create an optimal educational framework to enhance strategic thinking and design thinking, the authors examined two case studies. Both case studies were part of the TAD curricula, which worked as industrial-educational cooperation, tools for prototyping, collaborative projects with other teams, and guidance from faculty advisors.

\subsection{Case study 1: capstone course}

The course is primarily aimed at engineering, industrial design, and business students who are interested in the product development of investment or consumer goods. The number of students in class is 66. Students incorporate ideas from other academic fields and exchange these ideas with the corporate, commercial, and industrial sectors to design new business models and services perceived in microscopic and macroscopic visions. To create a product that satisfies the values of innovative design, manufacturability, and marketability, students learn about and experience four stages in product development: observation, conceptualization, prototyping, and evaluation.

To support students from different majors:

(1) Three professors from each department (technology, design, business) co-teach together. Workshops relating to theories and skills needed in each of the stages are conducted. In the problem finding stage, we try to help students think about the following perspectives in each area of psychology, business, and design.

\section{Psychology:}

- Phenomenology: to avoid reducing the main phenomenon to only one symptom;

- User research: to avoid reducing the main problem to only one root cause. 


\section{Business:}

- Needs identification: value propositions for customers/users;

- Market research: potential revenue streams for various customer segments.

\section{Design:}

- Form follows function: the shape should be based on the indented function or purpose;

- Not decorating at the end, consider the entire design process from the front stage.

In the solutions stage, we encourage students to consider:

\section{Psychology:}

- Various scenarios for different contexts, situations, and people;

- Depth to solve the user's problem.

\section{Business:}

- Operational plans: key activities/resources/partners required to develop and deliver values (including channels for distribution/customer service);

- Business feasibility: cost structure of the above (to be covered by revenue streams).

\section{Design:}

- How the initial context is executed and how successfully it is embedded into the output;

- Aesthetics and meticulous dexterity in sophistical way at the end.

(2) The companies provide the problems and financial support necessary in generating solutions, and propose a social enterprises challenge as a customized capstone project. Through a capstone workshop, an interdisciplinary team of 4-6 students conducts a live consulting project to create a product or a service to tackle the organization's specified challenge. The organization benefits through a set of fresh recommendations based on the innovative design of creative thinkers, while students gain experience by working on a real-world consultancy project.

(3) Coaches from respective industries offered practical advice and guidance for the design.

(4) Special lecturers from around the world provided technical and theoretical knowledge needed in the manufacturing and executing process either online or offline based on the appropriate circumstance. For example, one lecturer from Germany conducts a practical program lecture about using Adobe XD to create a mobile phone interface design to conduct user research and perform user tests, which is currently being developed as a working prototype. This lecture is efficiently conducted through Zoom Video Communications online lectures where students can interactively follow his instructions and practice together.

As a result, one of the teams completed a project with global insurance service group South Korea Allianz to improve the services and marketing strategy of its online insurance product "AllRight" and developed "Walker Hollic" a new health care service application. On July 7, 2019 they successfully presented their creative ideas on service provision and marketing plans at South Korea Allianz's headquarters. Impressed by the students' talent and potential, the corporate officials said, they are observed the passion and challenging spirit of the students, who successfully went from the stages of ideation and conceptualization to actual prototyping over the course of a year. Companies obtained proof of the concept solution to the provided challenge, supported by a research and design-led innovation process. 
In addition, the partner companies experienced the development process along with the students, and therefore gained tangible and intangible benefits through this learning experience.

The partner gains significantly by bringing an open co-creation mindset. Each company sponsor assigns a contact person for the student team who follows the process and contributes to the project. Consequently, this course offers companies new inspiration and solutions from the creative minds of students trained by strategic thinking and design thinking.

\subsection{Case study 2: creative thinking and visualization}

One of the courses from the culture and design management division, Creative Thinking and Visualization (CTV), was led by the author. It was a semester-long team project wherein students created a mock exhibition to learn exhibition design for curatorial planning. To make students utilize strategic thinking and design thinking methods, business elements such as the SWOT (strengths, weaknesses, opportunities, and threats) analysis, setting target factors and positioning segments, and completing a budget plan were included. Without these strategic aspects, they would have merely focused on the aspect of styling, which would not have resulted in feasible products for the real market.

As they were required to incorporate strategic thinking practices, students gained an understanding of market strategy, positioning of segments, and business aspects, which ultimately resulted in a successful model. Students with various interests were grouped into teams and collaborated to brainstorm ideas and the direction of the final work. Because this was a team project, each team defined the problems that needed to be solved and shared diverse ideas and feedback with each other. Cooperating as a team leads to greater goal achievement than working alone.

Thus, incorporating strategic thinking and design thinking helped students accomplish the task in a fulfilling way through complementary groupings and synergistic effects. It was also confirmed that students could develop creative strategic thinking and design thinking skills with systematic training.

\section{Data analysis}

As the authors had conducted case studies by teaching two classes - capstone course, and CTV - they gained perspectives about design thinking and strategic thinking from three main beneficiaries: educators, students, and design strategists who participated or co-taught the course. The results of the research questionnaire are presented as follows.

Korean educators agreed that design thinking in SK is perceived as part of the fine arts, is too heavily focused on the styling of products or services, and is characterized by a gap between theoretical and practical classes. Compared to Korean educators, foreign professors did not recognize that this problem exists in SK. This may be due to the perception that design thinking in SK is already excellent because of the outstanding design work produced by Korean companies like Samsung, LG Corporation, and Hyundai. Most educators in the interviews stated the value of strategic tools; however, some argued that over-reliance on these tools is dangerous because designers may stop thinking strategically. 


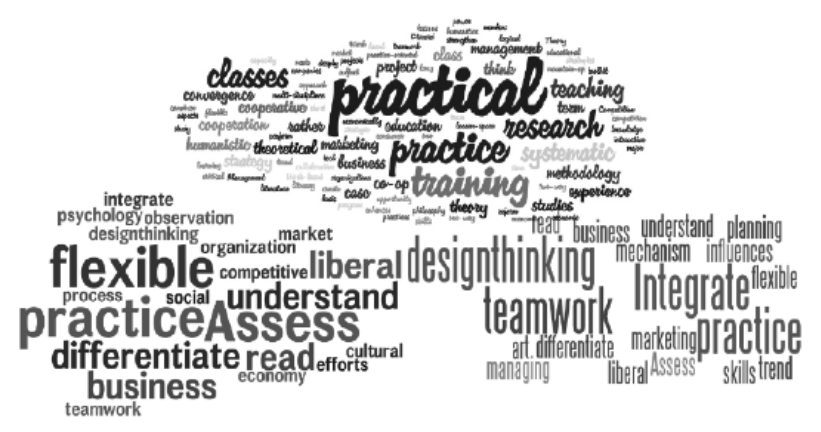

Figure 2. Results of the tag cloud analysis of the interviews (from left to right: educators, students, and design strategists) (source: created by authors)

In the student interviews, it was observed that business management-related contents and tools were helpful for pursuing their projects. These tools helped students gain a realistic overview of the budget, determine whether the project could be successfully launched in the market, and predict how well the product or service would sell. The focus group workshops revealed that interdisciplinary teamwork is a valid educational method. This method is most often utilized in design courses for other departments. During one focus group workshop, it was found that design students thought more strategically, particularly when they worked with engineering and business students.

While design strategists agreed upon the need for strategic thinking, they also pointed out that aesthetic designers are important. They stated that there should be a balance between aesthetic and strategic aspects in the design industry. Designers expressed a desire for more cooperative work between the industry and for schools to provide designers with inspiration and fuel students' passion. However, they were aware that students lack strategic thinking skills, and recommended that students develop sufficient practices and business perspectives.

Tag cloud analysis is a tool for strategic visual analysis of text data (Halvey \& Keane, 2007). Analyzing the interviews using tag cloud analysis (Figure 2) revealed that all three groups of beneficiaries recommended implementing practical applications in design thinking to enhance strategic thinking because learning about strategic thinking from a solely theoretical perspective is insufficient.

\section{Findings}

Based on the experiences and reflections from teaching these classes, the following guideline frameworks were drawn by two Korean professors including the author and two design experts who participated in the classes to develop the final framework for two years.

\subsection{Identifying key drivers for enhancing strategic thinking}

The study revealed numerous insights: (i) design undergraduates in SK have short-sighted mindsets that need to be reshaped; (ii) there is a need for increased practical interdisciplinary and multicultural applications of strategic thinking to bridge the gap between theoretical and practical classes; and (iii) consistent stimulation is required to internalize strategic thinking. 


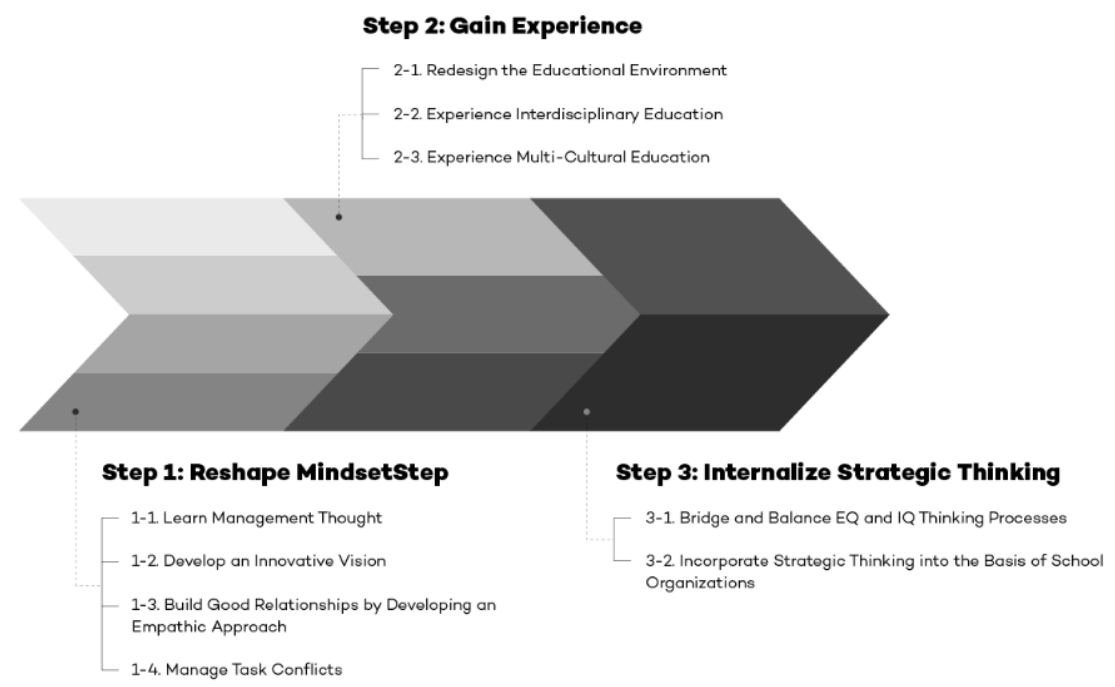

Note: EQ = emotional intelligence quotient; IQ = intelligence quotient.

Figure 3. Undergraduate educational framework in South Korea (source: created by authors)

Therefore, this research proposes an educational framework with three strategic steps focusing on the following: reshaping mindset, gaining experience, and internalizing strategic thinking. Combined, these steps, including nine specific guidelines on how to implement the framework depending on the level of the group (individuals, groups, and organizations), can help enhance Korean undergraduate students' strategic thinking (Figure 3).

\subsubsection{Step 1: reshaping mindset}

Previous research indicates that Korean design students are short-sighted and have an unclear understanding of strategic thinking. Therefore, there is a need to reshape students' strategic thinking and build a new mindset. At the individual level, design students in SK can reshape their strategic thinking by learning management thought and developing an innovative vision. As design strategy needs to be managed, students must gain management skills. Integrating an innovative perspective and future-oriented vision can help designers to develop appropriate strategic thinking because a strong vision is one of the main elements in strategic thinking theory (Bonn, 2005), and innovation is dependent upon design. At the group level, developing an empathic approach can build good, long-term relationships between educators and students. Holston (2011, p. 54) argued that empathy can result in good relationships between individuals by building trust, which enables us to collaborate to freely and creatively develop a strategy. Strategic thinking can compensate for students' lack of logical thinking and guide them to manage task conflicts at the group level. Task conflict refers to arguments that arise during a particular task (Jehn \& Mannix, 2001), and it can be positive because it stimulates the discussion of ideas, triggers an essential analysis of issues, and leads to better decisions. 


\subsubsection{Step 2: gaining experience}

Experience can be another key trigger to enhance strategic thinking. The best way to gain strategic experience is to engage in various experiences from multiple approaches. According to Jantsch (1972) and Pohl and Hirsch Hadorn (2007), these approaches can be categorized into six levels: disciplinary, multi-disciplinary, pluri-disciplinary, cross-disciplinary, interdisciplinary, and transdisciplinary. Regarding the current design education situation in SK, it is suggested that diverse experiences that stimulate students to think strategically are encouraged, and that interdisciplinary and multicultural approaches are adopted. This is because design education in SK is currently multi- and transdisciplinary, but in terms of multiple approaches to cultural interaction, SK is still in the early stages. Additionally, as most students in the in-depth interviews stated that the design education environment in SK is poorly suited to enhancing strategic thinking, it should be renovated. A good environment is important because people are more creative and strategic when their motivations are supported by an innovative environment.

\subsubsection{Step 3: internalizing strategic thinking}

To avoid the loss of learned information, our brains must be consistently stimulated. Therefore, to prevent students from losing their theoretical and practical strategic thinking skills, they must consciously internalize their strategic thinking capabilities. Individually, students can internalize their strategic thinking by bridging and balancing emotional intelligence (creative thinking) and intelligence quotient (analytical thinking). Integrating both thinking processes leads to more productive strategic thinking skills in terms of time efficiency and error reduction because it makes students critically consider product quality and process efficiency. At the organizational level, design education is needed to incorporate an organizational culture that enhances strategic thinking into the institution's organization. Developing a flexible structure is recommended to break down communication barriers between educators and students in SK. An organic organization that has a flexible structure can also emphasize coordination through horizontal communication.

\subsection{Evaluating the framework}

To evaluate the validity of the proposed framework from the perspectives of academia and industry, the framework was analyzed by two Korean professors including the author and two design experts who taught the case study classes for two years to develop the final framework. From the experts' evaluation and analysis, the proposed framework appeared to be a valid method to guide undergraduate design students in SK to develop appropriate strategic thinking. The framework suggests not only proper key drivers and disciplines in a step-by-step manner but also focuses on dealing with this problem in design education in SK.

However, the experts stated that this framework should explain the detailed methods through which key drivers can be achieved. To this end, a strategic implementation plan is suggested. Based on the evaluation, a refined proposed framework is presented in Figure 4. 

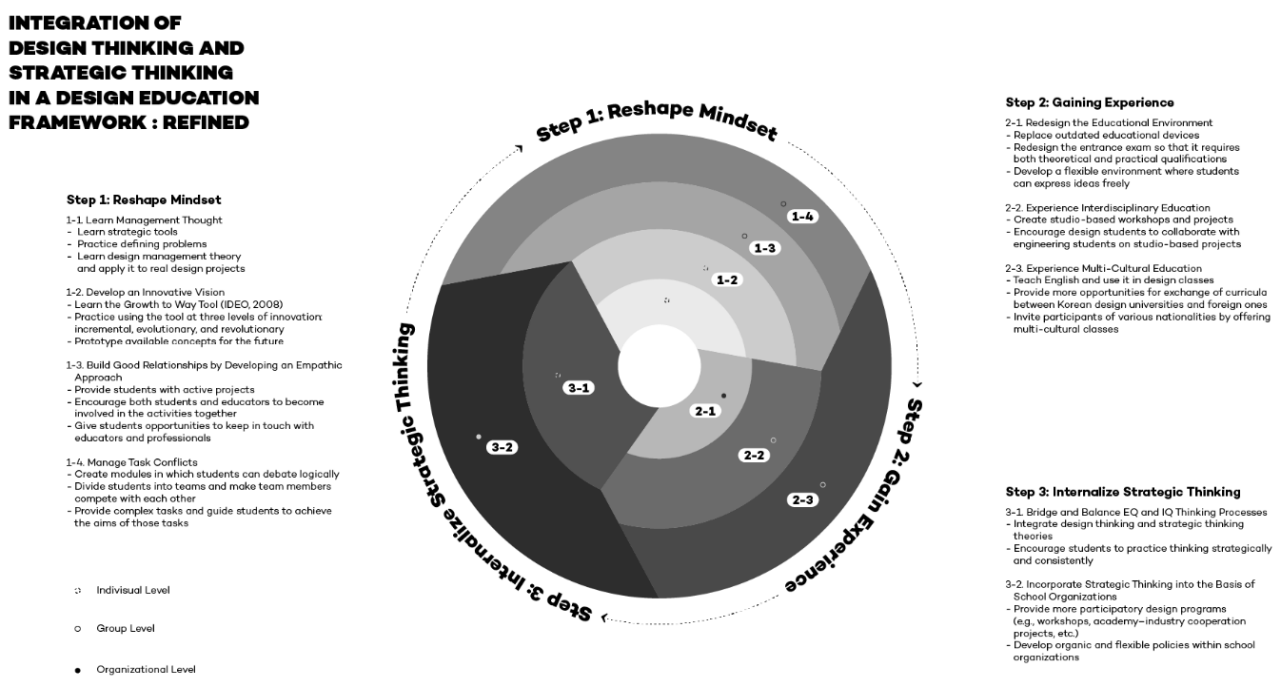

Figure 4. Refined framework incorporating specific implementation plans

(source: created by authors)

\section{Discussion (implementations of developed framework)}

In the refined framework, strategic implementation plans can be executed differently depending on the level (individual, group, or organizational). Studying strategic tools, such as PEST (political, economic, social, and technological) analysis, SWOT analysis, and the fishbone diagram in addition to design management theory is recommended to improve students' management thought. The SWOT analysis is one of the most widely used strategic planning tools (Mayo, 2020), and the PEST analysis is a strategic tool that emphasizes the local context (Peng \& Baptista Nunes, 2007). Furthermore, the fishbone diagram is a systematic technique for identifying the possible root causes of a problem (Tan \& Platts, 2005).

The Growth to Way Tool, introduced by Jacoby and Rodriguez (2007), is recommended to gain an innovative vision because it clearly identifies and describes innovation. At the group level, students should be encouraged to think strategically by incorporating debate into complex tasks to solve current serious problems such as environmental, social, and political issues. By becoming involved in active projects with educators, such as through roleplaying activities, students can develop close relationships with educators and become less reluctant to discuss ideas with them.

To encourage students to gain sufficient interdisciplinary and multicultural experiences, it is recommended that universities create studio-based workshops and projects that conduct discussions in English. In the multicultural classroom, teaching English should be the first step, as it is now the most widely used language in the world (Mydans, 2007). As discussed, mixing design with engineering disciplines helps to effectively enhance students' strategic thinking. 
By replacing outdated educational devices and redesigning entrance exams to ensure that they require both theoretical and practical qualifications, the design education environment can become a place for students to freely express their ideas. During the internalization step, educators should integrate design thinking theory with strategic thinking theory (as they work in tandem) and should strongly encourage students to consistently practice strategic thinking.

Providing more participatory design programs such as workshops and academy - industrial cooperation projects, and developing organic and flexible policies within school organizations are also recommended as solid implementation plans at the organizational level. If the culture of strategic thinking is pervasive in the school environment, the organization can be more organic and flexible, which helps students consistently enhance their strategic thinking in design education.

\section{Conclusions}

This research identified the growing demands of companies seeking graduates with strategic thinking and design thinking abilities. Additionally, it discussed current formal design education situations in the world, the problem of design education in SK, and the key barriers to and drivers of enhancing students' strategic thinking in SK. By empirically examining case study classes (the capstone class and the CTV class), the authors presented new guidelines for the undergraduate level on how the fields of design, technology, and business can be cooperated with theoretical contents and the skills students would need.

Subsequently, a valid strategic framework was proposed as recommendations to be adopted based on the research. The authors believe that the newly developed framework will contribute to the creation of an effective teaching strategy that nurtures students' strategic thinking and design thinking. Thus, it will lay the foundations for an undergraduate environment where design students are encouraged to think strategically and creatively. The goal of the integration of strategic thinking and design thinking at the undergraduate level is to develop students who will translate creativity into innovation by conceptualizing, designing, and managing new products and services for an innovative user experience while also valuing creation based on information, communication design, and technology. In many educational systems around the world, the category of strategic design and thinking management is presented as an interdisciplinary course during the master's degree; however, sufficient guidelines are not provided at the undergraduate level.

The researchers believe that this study will, therefore, enable design students to expand their abilities to think strategically and creatively, and develop into strategic designers capable of working not only in academia but also in modern industries.

Educators can adjust the proposed framework to suit different educational environments and situations; thus, this research contributes to design education in both SK and other countries that face similar problems. We also hope that students will be able to utilize the concepts of strategic thinking and design thinking skills to solve complex problems by understanding trends, market conditions, and consumer needs, and by incorporating their own expertise. 


\section{Funding}

This work was supported by the Yonsei University Research Grant of 2020.

\section{References}

Amabile, T. M., Hill, K. G., Hennessey, B. A., \& Tighe, E. M. (1994). The work preference inventory: assessing intrinsic and extrinsic motivational orientations. Journal of Personality and Social Psychology, 66(5), 950-967. https://doi.org/10.1037/0022-3514.66.5.950

Anderson, T. (2003a). Art education for life. The International Journal of Art and Design Education, 22(1), 58-66. https://doi.org/10.1111/1468-5949.00339

Anderson, T. (2003b). Using art criticism strategies in ethnographic research. Visual Arts Research, 29(57), 155-162.

Anderson, T. (2004). Why and how we make art, with implications for art education. Arts Education Policy Review, 105(5), 31-38. https://doi.org/10.3200/AEPR.105.4.31-36

Bonn, I. (2005). Improving strategic thinking: a multilevel approach. Leadership and Organization Development Journal, 26(5), 336-354. https://doi.org/10.1108/01437730510607844

Borja de Mozota, B. (2003). Design management: using design to build brand value and corporate innovation. Allworth Press.

Britannica. (2020). Creativity. https://www.britannica.com/topic/creativity/Research-on-the-creativeprocess

Brown, T. (2009a). Change by design: how design thinking transforms organizations and inspires innovation. HarperCollins Publishers.

Brown, T. (2009b). The making of a design thinker. Metropolis. https://www.metropolismag.com/ideas/ the-making-of-a-design-thinker/

Casakin, H. P. (2007). Metaphors in design problem-solving: implications for creativity. International Journal of Design, 1(2), 21-35.

DesignDB. (2020). Dijainsaneob Tonggye. http://www.designdb.com/?menuno=788\&bbsno=11774\&act=view\&ztag=rO0ABXQANDxjYWxsIHR5cGU9ImJvYXJkIiBubz0iNTkwIiBza2luPSJwaG90b 19iYnMiPjwvY2FsbD4\%3D

Design Management Institute. (2020). What is design thinking? https://www.dmi.org/page/WhatisDMI

Gaut, B., \& Livingston, P. (Eds.). (2003). The creation of art: new essays in philosophical aesthetics. Cambridge University Press.

Guilford, J. P. (1973). Characteristics of creativity. Springfield.

Halvey, M., \& Keane, M. T. (2007, 8-12 May). An assessment of tag presentation techniques. In C. Williamson \& M. E. Zurko (Eds.), WWW'07: Proceedings of the 16th International Conference on World Wide Web (pp. 1313-1314). Banff, Alberta, Canada. Association for Computing Machinery. https://doi.org/10.1145/1242572.1242826

Herrmann, M., \& Goldschmidt, G. (2013). Thinking about design thinking: a comparative study of design and business texts. In A. Chakrabarti \& R. V. Prakash (Eds.), ICoRD'13: Global Product Development (pp. 29-40). Series: Lecture Notes in Mechanical Engineering. Springer India. https://doi.org/10.1007/978-81-322-1050-4_3

Holston, D. (2011). The strategic designer: tools and techniques for managing the design process. HOW Books.

Jacoby, R., \& Rodriguez, D. (2007). Innovation, growth, and getting to where you want to go. Design Management Institute: Review, 18(1), 10-15. https://doi.org/10.1111/j.1948-7169.2007.tb00067.x 
Jantsch, E. (1972). Inter- and transdisciplinary university: a systems approach to education and innovation. Higher Education, 1, 7-37. https://doi.org/10.1007/BF01956879

Jehn, K. A., \& Mannix, E. A. (2001). The dynamic nature of conflict: a longitudinal study of intragroup conflict and group performance. The Academy of Management Journal, 44(2), 238-251. https://doi.org/10.2307/3069453

Kefallonitis, E. G. (2007). Foolproof design management education. Design Management Institute: Review, 18(3), 23-28. https://doi.org/10.1111/j.1948-7169.2007.tb00209.x

Kumar, V. (2009). A process for practicing design innovation. Journal of Business Strategy, 30(2/3), 91-100. https://doi.org/10.1108/02756660910942517

Kurzweil, R. (2004). Daniel H. Pink: The MFA Is the New MBA. Hardvard Business Review. https://hbr.org/2004/02/breakthrough-ideas-for-2004

Lee, H.-K., \& Breitenberg, M. (2010). Education in the New Millennium: the case for design-based learning. The International Journal of Art and Design Education, 29(1), 54-60. https://doi.org/10.1111/j.1476-8070.2010.01631.x

Martin, R. (2009). The design of business: why design thinking is the next competitive advantage. Harvard Business Review Press.

Mayo, D. T. (2020). Strategic planning tools. Reference for business. https://www.referenceforbusiness. com/management/Sc-Str/Strategic-Planning-Tools.html

McCullagh, K. (2008). Strategy for the Real World. In Th. Lockwood \& Th. Walton (Eds.), Building design strategy: using design to achieve key business objectives (pp. 67-78). Allworth Press.

Ministry of Knowledge Economy. (2013). Set Up a Committee for Integrated Design Education. Ministry of Knowledge Economy Announcement, 15 March, 2013 [unpublished source].

Mydans, S. (2007). Across cultures, English Is the Word. The New York Times. https://www.nytimes. com/2007/04/09/world/asia/09iht-englede.1.5198685.html?pagewanted=all\&_r=0

Nasi, J. (Ed.). (1991). Arenas of strategic thinking. Academic Bookstore.

Norman, D. (2013). The design of everyday things. Basic Books.

Peng, G. C. A., \& Baptista Nunes, M. (2007, 9-10 July). Using PEST analysis as a tool for refining and focusing contexts for information systems research. In Proceedings of the 6th European Conference on Research Methodology for Business and Management Studies (pp. 229-237). Lisbon, Portugal. Academic Conferences Limited.

Pohl, Ch., \& Hirsch Hadorn, G. (2007). Principles for designing transdisciplinary research. Oekom Verlag $\mathrm{GmbH}$.

Runco, M. A. (2007). Creativity. Theories and themes: research, development, and practice. Elsevier Academic Press.

Sarkar, P., \& Chakrabarti, A. (2011). Assessing design creativity. Design Studies, 32(4), 348-383. https://doi.org/10.1016/j.destud.2011.01.002

Shin, D., \& Kim, J. (2012). An improvement scheme of curriculum for major courses of visual communication design-focused on foundation studies courses of undergraduate studies. Chung-Ang University, Seoul, South Korea [unpublished source].

Tan, K. H., \& Platts, K. (2005). Effective strategic action planning: a process and tool. Business Process Management Journal, 11(2), 137-157. https://doi.org/10.1108/14637150510591147

Woyke, E., \& Atal, M. (2007). The talent hunt: design programs are shaping a new generation of creative managers. Bloomberg. https://www.bloomberg.com/news/articles/2007-10-04/the-talent-huntbusinessweek-business-news-stock-market-and-financial-advice

Zaki Dib, C. (1988, 20-24 July). Formal, non-formal and informal education: concepts/applicability. In J. Barojas (Ed.), Cooperative Networks in Physics Education: Conference Proceedings, Vol. 173. InterAmerican Conference on Physics Education (pp. 300-315). Oaxtepec, Mexico. American Institute of Physics. https://doi.org/10.1063/1.37526 